Randomised controlled trial

Non-opioid analgesia is as effective as opioid management in acute pain and supports a change in prescribing practice to help address the 'opioid epidemic'

10.1136/eb-2018-102877

Check for updates

Amelia Swift ${ }^{1,2}$

${ }^{1}$ Department of Nursing, University of Birmingham, Birmingham, UK, ${ }^{2}$ Integrated Clinical Academic Office, University Hospitals Birmingham NHS Foundation Trust, Birmingham, West Midlands, United Kingdom

Correspondence to: Dr Amelia Swift, Department of Nursing, University of Birmingham, Birmingham B15 2TT, UK; A.Swift@bham.ac.uk

Commentary on: Chang AK, Bijur PE, Esses D, et al. Effect of a single dose or oral opioid and non-opioid analgesics on acute extremity pain in the emergency department: a randomised controlled clinical trial. JAMA 2017;318:1661-7.

\section{Implications for practice and research}

- In some emergency department patients, combinations of non-opioid analgesia may be as effective in reducing pain as opioids.

- Using non-opioid analgesia as a first-line treatment in short-term moderate to severe trauma pain might contribute to reducing longterm dependence on opioids.

- Further research into dosing, adverse events, patient satisfaction and analgesia combinations in other patient groups is required.

\section{Context}

Opioid analgesics are the first-line treatment for moderate to severe pain in the emergency department (ED) despite concerns about the 'opioid epidemic'. The opioid epidemic refers to a rapid increase in the use of opioids in the USA and Canada that began in the 1990s, recently reframed as a public health emergency. ${ }^{1}$ Long-term opioids use often begins with a prescription for an acute pain problem, ${ }^{2}$ and is associated with an increased risk of dependence. ${ }^{3}$

The aim of this study was to determine whether non-opioid analgesia could be as effective in managing moderate to severe acute extremity pain as opioid analgesia. ${ }^{4}$

\section{Methods}

Adult patients attending one of two EDs in New York with pain in the arm or leg were randomised to one of four groups. They provided pain scores using an 11-point numerical rating scale (NRS) and were then given either $400 \mathrm{mg}$ ibuprofen and $1000 \mathrm{mg}$ paracetamol (called acetaminophen throughout the article as this was based in the USA) or $5 \mathrm{mg}$ oxycodone and $325 \mathrm{mg}$ paracetamol, or $5 \mathrm{mg}$ oxycodone and $300 \mathrm{mg}$ paracetamol, or $30 \mathrm{mg}$ codeine and $300 \mathrm{mg}$ paracetamol. Mean change in pain and use of rescue analgesia were used as the main outcome measures.

\section{Findings}

A total of 411 patients took part in the study. All the analgesia regimes were effective in reducing pain between 3.5 and 4.4 NRS points: there was no statistically significant difference between them. Eighteen per cent of patients took rescue medication during the trial but there was no difference in the proportion from each of the groups.

\section{Commentary}

Opioid medication and non-opioids provided similar levels of pain relief, challenging the perception that non-opioids are less effective in acute pain.

Numbers needed to treat (NNT) information for single-dose analgesia in a range of acute pain conditions has been available for some time. ${ }^{5}$ NNT provides a simple means of comparing different treatments. In terms of acute pain, an NNT of 3 means that when three people are given the treatment one of them will get at least 50\% reduction in their pain. Intramuscular morphine given in a dose of $10 \mathrm{mg}$ has an NNT of 2.9, while paracetamol with ibuprofen an NNT between 1.5 and 1.6 depending on the dose. ${ }^{6}$

The growing concern about the harms of opioids and this will provide an impetus to change, including new legislation and increased prescription monitoring in the USA. ${ }^{7}$

Larger studies are needed to strengthen this evidence for change. Future research should focus on effectiveness and factors such as patient expectations and satisfaction with treatment. It will be complicated to unravel whether a change in prescribing practice in the ED leads to a reduction in opioid dependence, but current evidence suggests that this is logical.

Competing interests None declared.

Provenance and peer review Commissioned; internally peer reviewed.

๑ Article author(s) (or their employer(s) unless otherwise stated in the text of the article) 2018. All rights reserved. No commercial use is permitted unless otherwise expressly granted.

\section{References}

1. Gostin LO, Hodge JG, Noe SA. Reframing the Opioid Epidemic as a National Emergency. JAMA 2017;318:1539-40.

2. Shah A, Hayes CJ, Martin BC. Characteristics of Initial Prescription Episodes and Likelihood of Long-Term Opioid Use - United States, 2006-2015. MMWR Morb Mortal Wkly Rep 2017;66:265-9.

3. Ciesielski T, Iyengar R, Bothra A, et al. A Tool to Assess Risk of De Novo Opioid Abuse or Dependence. Am J Med 2016;129:699-705.

4. Chang AK, Bijur PE, Esses D, et al. Effect of a single dose of oral opioid and nonopioid analgesics on acute extremity Pain in the emergency department: a randomized controlled clinical trial. JAMA 2017;318:1661-7.

5. Oxford Pain Group. Oxford league table of analgesics in acute pain. 2007 http:// www.bandolier.org.uk/booth/painpag/Acutrev/Analgesics/Leagtab.html

6. Moore RA, Wiffen PJ, Derry S, et al. Non-prescription (OTC) oral analgesics for acute pain - an overview of Cochrane reviews. Cochrane Database Syst Rev 2015;11:CD010794.

7. Hoback J. OVERDOSED ON OPIOIDS: A deadly opioid epidemic sweeping the country has lawmakers working hard to find solutions. State Legis 2016;42:9-13. 